\title{
Causas de condenações post-mortem de perus abatidos em estabelecimento com Serviço de Inspeção Federal (SIF) no estado de Minas Gerais, Brasil
}

\author{
Causes of post-mortem condemnations of slaughtered turkeys in an \\ establishment with Federal Inspection Service (FIS) in the state \\ of Minas Gerais, Brazil
}

\author{
Mariela Silva Moura, ${ }^{*}$ Dênio Oliveira Reis, ${ }^{* *}$ Rafael Silveira Carreon, ${ }^{* *}$ Lúcio Borges de Araújo, ${ }^{* * *}$ \\ Mirian Fernandes Carvalho Araújo, ${ }^{* * *}$ Kênia de Fátima Carrijo, ${ }^{* *}$ Rone Cardoso****
}

\begin{abstract}
Resumo
Este estudo objetivou identificar as principais causas de condenações de perus abatidos sob Serviço de Inspeção Federal, além de verificar as estações do ano em que as condenações são mais frequentes. Foram utilizados dados do Serviço de Inspeção Federal de um matadouro-frigorífico exportador de aves localizado na mesorregião do Triângulo Mineiro e Alto Paranaíba, Minas Gerais, no período compreendido entre agosto de 2008 a julho de 2009. Foram inspecionadas 8.153.866 aves, procedentes de 19 municípios localizados nesta mesorregião. Destas, 1.767 .503 (21,68\%), tiveram algum tipo de condenação post-mortem. As principais causas de condenação (parcial e total) foram agrupadas segundo o mês e estação do ano, a fim de se verificar quais foram as condenações de maior e menor frequência. Foram condenados parcialmente 1.750 .863 perus $(21,47 \%)$ e $16.640(0,21 \%)$ foram condenados totalmente. Dentre o número total de condenações post-mortem, $99,06 \%$ foi devido a condenações parciais e $0,94 \%$ devido a condenações totais. As causas de condenação parcial mais frequentes foram devido à aerossaculite $(41,24 \%)$, seguida de contaminação biliar (23,73\%). As causas de condenação total mais frequentes foram em função de aspecto repugnante $(51,62 \%)$ e dermatose $(22,71 \%)$. A estação do ano que apresentou maior frequência de condenações tanto totais quanto parciais foi a primavera. Verificou-se que na mesorregião analisada, as condenações encontradas foram em sua maioria, em função de causas infecciosas, sugerindo uma melhoria no manejo sanitário dos animais durante a criação, sobretudo na primavera.
\end{abstract}

Palavras-chave: Abate, condenações, peru, SIF.

\begin{abstract}
This study aimed to identify the main reasons of condemnation of turkeys slaughtered under Federal Inspection Service and to verifying the seasons of the year in which condemnations are more frequent. For the analysis, were used the data from one Federal Inspection Service of a poultry slaughter plant located at the "Triângulo Mineiro" and "Alto Paranaíba" region, "Minas Gerais", during the period from august 2008 to july 2009 . Were inspected 8,153,866 turkeys from 19 cities located in this mesoregion. Of these, $1,767,503(21.68 \%)$ had some type of post-mortem condemnation. The main causes of condemnation (partial and total) were grouped by month and season, in order to determine what were the condemnations of greater and lesser frequency in turkeys slaughtered during the period analyzed. 1,750,863 (21.47\%) turkeys were partial condemned and 16,640 $(0.21 \%)$ were totally condemned. Among the total number of condemnations post-mortem, $99.06 \%$ was due to partial condemnations and $0.94 \%$ was due to total condemnations. The causes of partial condemnations more frequent were aerial sacs infection (41.24\%) followed by bile contamination (23.73). The causes of total condemnation were all more frequent due to repugnant aspect $(51.62 \%)$ and dermatosis $(22.71 \%)$. The season with the highest frequency of both total and partial condemnations was the spring. It was found that in the analyzed region, the condemnations were found mostly due to infectious causes, suggesting an improvement in the sanitary handling of animals during the creation, especially in the spring.
\end{abstract}

Keywords: Condemnation, slaughter, FIS, turkey.

\footnotetext{
*Laboratório de Biotecnologia Animal Aplicada, Faculdade de Medicina Veterinária, Universidade Federal de Uberlândia (UFU), Av. Ceará s/n, Bairro Umuarama, Bloco 2D, sala 43, Uberlândia, MG 38405-303, Brasil. A quem enviar a correspondência. E-mail: marielasmoura@yahoo.com.br.

${ }^{* *}$ Faculdade de Medicina Veterinária, Universidade Federal de Uberlândia (UFU), Av. Ceará s/n, Bairro Umuarama, Bloco 2T, Uberlândia, MG 38405-303, Brasil.

***Faculdade de Matemática, Universidade Federal de Uberlândia (UFU), Av. João Naves de Ávila 2121, Bloco 1F, Uberlândia, MG 38408-100, Brasil.

*** Instituto de Genética e Bioquímica (INGEB), Universidade Federal de Uberlândia (UFU), Av. Pará 1720, Bairro Umuarama, Bloco 2E Sala 34, Uberlândia, MG 38400-902, Brasil.
} 


\section{Introdução}

O agronegócio avícola brasileiro representa uma importante fonte de divisas para o país, pois movimenta bilhões de dólares ao ano, representando $1,5 \%$ do Produto Interno Bruto (PIB) (Cepea, 2012).

A produção de carne de frango chegou a 12,230 milhões de toneladas em 2010 , em um crescimento de $11,38 \%$ em relação a 2009. O crescimento em 2010 foi impulsionado principalmente pelo aumento de consumo de carne de frango e pela expansão de $5,1 \%$ nas exportações. Do volume total de frangos produzido pelo país, $69 \%$ foi destinado ao consumo interno e $31 \%$ para exportações, as quais geraram uma receita cambial de US\$ 6,808 milhões (Ubabef, 2011). Além disso, emprega 4,5 milhões de pessoas, em suas atividades diretas e indiretas (Cepea, 2012). Acompanhando o mesmo ritmo, a criação de perus vem se tornando altamente especializada, obrigando cada vez mais os produtores e a indústria a buscarem novas tecnologias. Esse fato decorre basicamente devido ao crescente consumo interno e aumento das exportações de carne e derivados de peru (Pulici et. al. 2008). No ano de 2010 , foram produzidas 337 mil toneladas de carne de peru, sendo que destas, 157.820 foram destinadas à exportação, gerando uma receita cambial de US\$ 424,4 milhões. O maior volume de embarques foi de industrializados (79.758 toneladas), sendo que o principal mercado comprador foi a Europa, com 87.240 toneladas (Ubabef, 2011).

Em função da crescente exportação e da globalização de mercados, as barreiras sanitárias ganharam destaque e representam o diferencial de competitividade no mercado internacional. Baseado no aumento da produção, consumo e exportação de carne de aves, além da preocupação com o risco de doenças transmitidas por alimentos, o Serviço de Inspeção Sanitária é de fundamental importância na orientação e fiscalização da integridade deste processo como um todo, a fim de garantir aos consumidores um alimento que além de apresentar um valor nutricional satisfatório, seja sobretudo, seguro (Macahyba et al. 2005).

Além de monitorar a etapa de pré-abate e as tecnologias utilizadas no abate e pós-abate, o serviço de inspeção sanitária é responsável por identificar lesões em carcaças e vísceras na inspeção post-mortem, retirando da linha os casos anormais e ou suspeitos e conduzi-los ao Departamento de Inspeção Final (DIF), para o julgamento e destino adequado. Este procedimento visa oferecer maior garantia de que os consumidores terão acesso a alimentos inócuos, além de obter dados nosológicos para que medidas sanitárias possam ser implementadas.

Com essa preocupação, e em função da escassez de informações sobre as principais causas de condenação postmortem de perus no Brasil, sobretudo em Minas Gerais, o presente trabalho teve por objetivo identificar as principais causas de condenação parcial e total de perus abatidos sob inspeção sanitária federal, além de verificar as estações do ano em que as condenações são mais freqüentes em um matadourofrigorífico exportador da mesorregião do Triângulo Mineiro e Alto Paranaíba, Minas Gerais.

\section{Material e métodos}

Para a realização desta pesquisa, utilizou-se dados oficiais do Serviço de Inspeção Federal (SIF) de um matadouro-frigorífico exportador localizado na mesorregião do Triângulo Mineiro e
Alto Paranaíba, Minas Gerais. Os dados referiam-se a perus que foram abatidos durante o período de agosto de 2008 a julho de 2009, sendo estes dados distribuídos segundo o mês e principais causas de condenação (parcial e total).

Durante o período analisado, foram abatidos 8.153 .866 perus, procedentes de 19 municípios localizados na mesorregião do Triângulo Mineiro e Alto Paranaíba, Minas Gerais. O procedimento de inspeção post-mortem nos mesmos foi efetuado conforme o determinado pelo Regulamento da Inspeção Industrial e Sanitária de Produtos de Origem Animal - RIISPOA (Brasil 2008) e Portaria n² 210 (Brasil 1998), a partir do exame visual macroscópico das carcaças e suas respectivas vísceras nas chamadas "Linhas de Inspeção" ("A", "B" e "C"). Cada carcaça era examinada individualmente e as diversas causas de condenação, quando existentes, eram marcadas no ábaco. Posteriormente estes dados eram transcritos para fichas padronizadas, especificando-se as causas de condenação, tanto parciais quanto totais.

Após a obtenção dos dados, estes foram dispostos em tabelas e analisados estatisticamente. Foi realizada uma análise descritiva dos dados, para determinar o percentual de carcaças condenadas totalmente e parcialmente na inspeção postmortem, as condenações de maior e menor frequência durante todo o período analisado, dentro de cada mês e por estação do ano.

\section{Resultados e discussão}

O estudo sobre a ocorrência de condenações de perus abatidos sob inspeção sanitária federal, apesar de sua importância para a sanidade avícola e inspeção higiênico-sanitária e tecnológica, apresenta poucos estudos (Macahyba et al. 2005 e Schlestein 2007) sobre esta espécie (Meleagris gallopavo), o que dificulta a comparação dos resultados obtidos no presente trabalho com outras pesquisas semelhantes.

\section{Aves Abatidas x Condenações Post-mortem}

Das 8.153.866 aves abatidas, 1.767 .503 (21,68\%), tiveram algum tipo de condenação post-mortem. Foram condenados parcialmente 1.750 .863 perus $(21,47 \%)$ e $16.640(0,21 \%)$ foram condenados totalmente. Nota-se que o percentual de perus condenados parcialmente (ou seja, $99,06 \%$ do número total de condenações) foi muito superior ao de perus condenados totalmente $(0,94 \%$ do número total de condenações), conforme pode-se observar na tabela 1 .

Tabela 1: Condenações parciais e totais post-mortem e seus respectivos percentuais sobre 1.767 .503 perus condenados, no período agosto de 2008 a julho de 2009

\begin{tabular}{lrr}
\hline Critério de condenação post-mortem & $\mathrm{N}$ & \multicolumn{1}{c}{$\%$} \\
\hline Condenação parcial & 1.750 .863 & 99,06 \\
Condenação total & 16.640 & 0,94 \\
\hline Total de condenações & 1.767 .503 & 100 \\
\hline
\end{tabular}

Macahyba et al. (2005) e Schlestein (2007) também encontraram percentuais de condenação parcial superiores ao de condenação total no estado de Santa Catarina e no estado do Rio Grande do Sul, respectivamente. Este tipo de condenação é normalmente 
o mais freqüente na rotina de inspeção post-mortem, visto que, aquelas aves que apresentam alguma alteração, desde que não seja generalizada, serão aproveitadas após a remoção das partes atingidas, dando-se destino adequado segundo os critérios do inspetor médico veterinário do estabelecimento. Já o percentual encontrado de condenações totais $(0,21 \%$ do total de aves abatidas), foi muito inferior aos que foram encontrados por Macahyba et al. (2005) (1,11\%) e Schlestein (2007) (0,6\%), demonstrando que, na presente pesquisa, além das aves apresentarem um status sanitário satisfatório, as manobras tecnológicas executadas no manejo pré-abate foram bem conduzidas, evitando-se condenações totais.

\section{Condenações parciais}

As causas de condenação parcial durante o período analisado podem ser observadas na Tabela 2.

Tabela 2: Quantidades e percentuais das principais causas de condenaçãoparcial sobreototal de perus condenados parcialmente em um matadouro-frigorífico exportador de Minas Gerais sob inspeção sanitária federal, no período entre agosto de 2008 e julho de 2009

\begin{tabular}{lcc}
\hline $\begin{array}{l}\text { Causas de condenação } \\
\text { parcial }\end{array}$ & $\mathbf{N}$ & $\%$ \\
\hline Abscesso & 1.763 & $0,10 \%$ \\
Aerossaculite & 722.119 & $41,24 \%$ \\
Artrite & 163.787 & $9,35 \%$ \\
Celulite & 16 & $0,00 \%$ \\
Colibacilose & 1.991 & $0,11 \%$ \\
Contaminação fecal & 293.818 & $16,78 \%$ \\
Contaminação biliar & 415.401 & $23,73 \%$ \\
Contusão & 136.469 & $7,79 \%$ \\
Dermatoses & 9.327 & $0,53 \%$ \\
Escaldagem excessiva & 46 & $0,00 \%$ \\
Evisceração retardada & 5 & $0,00 \%$ \\
Sangria inadequada & 6.121 & $0,35 \%$ \\
\hline Total & $\mathbf{1 . 7 5 0 . 8 6 3}$ & $\mathbf{1 0 0 , 0 0 \%}$ \\
\hline
\end{tabular}

A causa de condenação parcial mais frequente encontrada neste trabalho foi a aerossaculite, sendo responsável por $41,24 \%$ do total de aves condenadas neste grupo. Esta inflamação dos sacos aéreos também foi a causa de condenação parcial mais freqüente descrita por Macahyba et al. (2005), que atribuíram a esta inflamação um percentual de $89,23 \%$ das condenações parciais em perus abatidos no estado de Santa Catarina. No entanto, para Schlestein (2007) esta foi a sexta maior causa de condenação parcial, com um percentual de 5,71\%, uma vez que a maior causa de condenação parcial encontrada por este autor foi devido às contusões e fraturas. Macahyba et al. (2005) justificam que o índice elevado de areossaculite devese à dinâmica populacional dos animais, pois uma única ave doente tem a capacidade de disseminar a enfermidade para todo plantel. Além disso, Herenda e Franco (1996) e Castro (2000) comentam que os sacos aéreos em aves são estruturas facilmente colonizáveis por agentes infecciosos, de modo que os mesmos são altamente susceptíveis ao desenvolvimento de lesões. O menor percentual encontrado para esta causa de condenação no presente trabalho, quando comparado a Macahyba et al. (2005) pode ser atribuído, possivelmente, à adoção de medidas de saneamento e biosseguridade mais rígidas nas granjas de onde as aves procederam, uma vez que a etiologia da aerossaculite estão relacionadas à má qualidade do ar e à poeira do ambiente, juntamente com a associação de outros agentes virais ou Mycoplasma spp. (Herenda e Franco, 1996). Além disso, como não se utiliza vacinas para perus, com a finalidade de prevenir a infecção por Mycoplasma gallisepticum, o controle desta é feito com base nas medidas anteriormente citadas, além da adoção de tratamento com antimicrobianos específicos para este agente (Back e Oliveira, 2006). Macahyba et al (2005) afirmam ainda que altos índices de aerossaculite estão relacionados ao clima, sendo mais frequentes em épocas que as temperaturas ambientais são mais elevadas.

Já a segunda maior causa de condenação parcial foi devido à contaminação biliar $(23,50 \%)$, seguida de contaminação fecal, responsável por $16,62 \%$ deste grupo de contaminações. Schlestein (2007) e Macahyba et al. (2005) agruparam as condenações atribuídas às diferentes contaminações, relatando percentuais de $15,58 \%$ e $3,63 \%$, respectivamente.

Dickel (2006) aponta que um motivo comum de condenação devido à contaminação fecal, é a não retirada da ração das aves em tempo determinado pela legislação (6 horas antes do abate), implicando na contaminação das carcaças durante a evisceração. Mendes (2001) relata também que jejuns pré-abate prolongados determinam uma maior contaminação devido à fragilidade intestinal e desidratação da carcaça, além de que, a elevação do $\mathrm{pH}$ intestinal que o jejum prolongado ocasiona, aumenta a proliferação de microrganismos patogênicos, com bactérias dos gêneros Salmonella e Listeria. Além do período de jejum prolongado, que pode influenciar no índice de contaminação fecal, deve-se ressaltar que dentro da empresa estudada, não há maquinário para evisceração automática, ou seja, a retirada das vísceras é feita de forma manual, o que talvez possa contribuir com o elevado número de contaminações tanto fecais quanto biliares, caso os funcionários que realizam estas operações não estejam bem capacitados.

A quarta maior causa de condenação parcial foi devido à artrite $(9,35 \%)$, que pode ter origem tanto infecciosa, quanto não infecciosa. Este resultado se aproxima daquele descrito por Schlestein (2007), que encontrou um percentual de $7,40 \%$. No entanto, é discordante daquele mencionado por Macahyba et al. (2005), que encontraram $0,19 \%$. A origem não infecciosa deste tipo de lesão deve-se à combinação de seleção genética, nutrição e manejo com o objetivo de maximizar o ganho de massa muscular das aves em curto espaço de tempo, podendo, segundo Fallavena (2000) e Thorp (1999), resultar em disfunções locomotoras traduzidas inicialmente por alterações nos hábitos alimentares, pior conversão alimentar, aumento de refugos e, posteriormente, elevada condenação no abate. Já a origem infecciosa desta inflamação, pode ter como agente etiológico, vírus (reovírus) e bactérias, como Staphylococcus sp. e Mycoplasma synoviae (Mcmullin et al. 1983 e Fallavena 2000). Como não se buscou verificar a origem das artrites, a fim de classificá-las como infecciosas ou não infecciosas, não é possível fazer inferências se as mesmas são decorrentes de problemas sanitários ou em função de transtornos locomotores. 
A frequência de condenações parciais devido a contusões $(7,79 \%)$, que refletem as condições do manejo pré-abate das aves (apanha, transporte, retirada das gaiolas e pendura), foi inferior ao valor encontrado por Schlestein (2007), que verificou um percentual de $36,42 \%$ no Rio Grande do Sul e concluiu que o manejo pré-abate e o processo de abate devem ser melhorados, já que as condenações relativas a este parâmetro estavam muito elevadas. No entanto, Macahyba et al. (2005), encontraram um percentual de $0,11 \%$ para esta condenação parcial, inferior ao encontrado no presente trabalho. Deve-se ressaltar que tanto Macahyba et al (2005) e Schlestein (2007), incluíram num mesmo grupo, tanto a frequencia de condenações por contusões quanto a de fraturas, enquanto que no presente trabalho não foi determinado o percentual de fraturas. Esta baixa freqüência de contusões encontradas nas aves abatidas no estabelecimento analisado, quando comparado à frequência descrita por Schlestein (2007), possivelmente reflete os esforços despendidos pela equipe de fomento quanto à capacitação dos profissionais envolvidos nas etapas que antecedem o abate das aves, a fim de atender os preceitos de bem-estar animal e abate humanitário, refletindo diretamente no baixo percentual de condenações. No entanto devem ser melhorados, a fim de atingir percentuais ainda mais baixos, como aqueles descritos por Macahyba et al. (2005).

\section{Condenações totais}

Observa-se na tabela 3 que a principal causa de condenação no grupo das condenações totais foi devido a aspecto repugnante, responsável por $51,62 \%$ das condenações. Esta causa de condenação refere-se àquelas carcaças que se enquadram nos artigos 172 e 236 do RIISPOA (Brasil 2008), isto é, aquelas que apresentam coloração anormal, mau cheiro, crepitação gasosa à palpação ou que exalam odores medicamentosos, excrementiciais, sexuais e outros considerados anormais. Esta também foi a maior causa de condenação total de perus encontrada por Schlestein (2007) no estado do Rio Grande do Sul, perfazendo $43,61 \%$ das condenações. Segundo os achados de Macahyba et al. (2005), que avaliaram perus abatidos no estado de Santa Catarina, esta foi a segunda maior causa de condenação total, responsável por $25,77 \%$ destas condenações. Este alto percentual pode estar relacionado às carcaças que apresentam coloração escura na musculatura, sem outras lesões, conforme citado por Herenda e Franco (1996) que comprometem as características sensoriais da carne e da carcaça, ou ainda devido a patologias de comprometimento sistêmico. Giotto (2008) avaliou o impacto econômico que esta alteração gerou num matadouro de frangos da região oeste do estado de Santa Catarina, e concluiu que a mesma representa um dos maiores problemas na indústria avícola brasileira em termos de condenações por causas patológicas.

Neste estudo, a segunda causa de condenação total foi devido a dermatose ou dermatite $(22,71 \%)$, patologia esta caracterizada por alterações de pele, envolvendo aumento da espessura e modificações de sua coloração. Esta foi a principal causa de condenação nos achados de Macahyba et al. (2005), responsável por $32,48 \%$ das condenações. Esta diferença pode supostamente estar relacionada às diferenças no manejo e no ambiente onde os animais foram criados, uma vez que possíveis causas desta alteração estão relacionadas a altas concentrações de amônia, ventilação insuficiente, cama molhada e outros fatores associados a ela (Teixeira, 2008).
Tabela 3: Quantidades e percentuais das principais causas de condenação total sobre o total de perus condenados totalmente em um matadouro-frigorífico exportador de Minas Gerais sob inspeção sanitária federal, no período entre agosto de 2008 e julho de 2009

\begin{tabular}{lcc}
\hline $\begin{array}{l}\text { Causas de condenação } \\
\text { total }\end{array}$ & $\mathbf{N}$ & $\%$ \\
\hline Abscesso & 9 & $0,05 \%$ \\
Aerossaculite & 27 & $0,16 \%$ \\
Artrite & 24 & $0,14 \%$ \\
Aspecto repugnante & 8.589 & $51,62 \%$ \\
Caquexia & 294 & $1,77 \%$ \\
Celulite & 4 & $0,02 \%$ \\
Colibacilose & 2.801 & $16,83 \%$ \\
Contusão & 27 & $0,16 \%$ \\
Dermatoses & 3.779 & $22,71 \%$ \\
Escaldagem excessiva & 163 & $0,98 \%$ \\
Evisceração retardada & 870 & $5,23 \%$ \\
Sangria inadequada & 23 & $0,14 \%$ \\
Contaminação Biliar & 25 & $0,15 \%$ \\
Canibalismo & 5 & $0,03 \%$ \\
\hline Total & 16.640 & $100,00 \%$ \\
\hline
\end{tabular}

A terceira maior causa de condenação total foi devido à colibacilose $(16,83 \%)$, termo empregado para designar as infecções causadas por Escherichia coli (Ferreira e Knöbl 2000). Esta foi a quarta e quinta principais causas de condenação de perus avaliados por Macahyba et al. (2005) e Schlestein (2007), que encontraram, respectivamente, $12,16 \%$ e $0,57 \%$. Este maior percentual encontrado no presente estudo, em relação àqueles descritos pelos autores supracitados pode ser justificado pela maior presença deste microrganismo no ambiente e/ou fatores que predispõem sua instalação, uma vez que o mesmo age como agente secundário de infecção respiratória, podendo se manifestar na forma de artrite, sinovite, osteomielite, peritonite, onfalite e septicemia (Back e Oliveira, 2006)

Pode-se verificar que a maiorias das causas de condenação total são multifatoriais e está relacionada a problemas de manejo sanitário ao longo da criação das aves, culminando com o desenvolvimento de lesões de causa infecciosa.

\section{Condenações Post mortem x Estação do ano}

A estação do ano que apresentou maior frequência de condenações tanto totais quanto parciais foi a primavera, conforme pode-se observar na figura 1 (constituída dos meses de outubro, novembro e dezembro), seguida de inverno, verão e outono, respectivamente. Estes dados concordam com aqueles que foram citados por Herenda e Franco (1996), onde os maiores índices de condenações foram encontrados no inverno e na primavera. No entanto, discordam daqueles que foram encontrados por Fabrício (1994), que obtiveram maiores índices de condenação de frangos de corte no verão, justificando tal achado ao fato de ser esta a estação em que ocorrem as temperaturas mais altas do ano. Esta inconformidade de resultados pode ser justificada possivelmente, pelo fato 


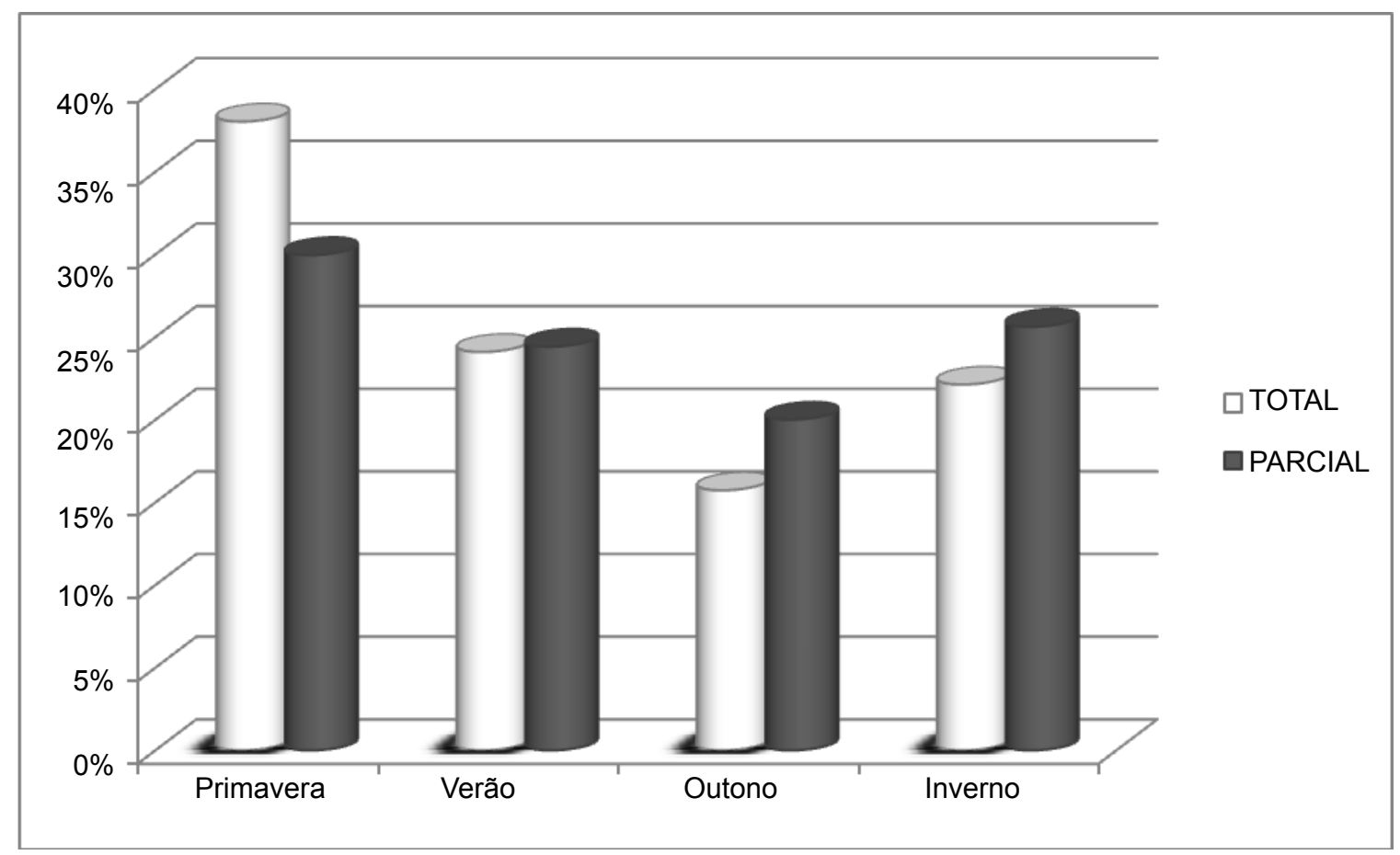

Figura 1: Comparação das frequências de condenação total e parcial de perus, sobre 1.767 .503 perus condenados em um matadouro-frigorífico exportador de Minas Gerais, sob inspeção sanitária federal no período entre agosto de 2008 e julho de 2009 , segundo a estação do ano

de que o ciclo de produção de perus comerciais nos aviários até atingir a idade de abate é mais longo que o de frangos de corte (Schlestein 2007). Dessa forma, este maior tempo de permanência no campo expõe a ave a um maior risco de adquirir doenças, e assim, a influência da temperatura deixa de ter o mesmo impacto sobre a imunidade das aves, como ocorre no caso de frangos de corte. Os resultados ainda diferem daqueles apresentados por Macahyba et al. (2005), que também verificaram maiores índices de condenação de perus no verão, os quais foram criados em Santa Catarina. Esta diferença pode ser supostamente atribuída às diferenças climáticas entre as regiões geográficas onde as aves foram criadas.

\section{Referências}

BACK, A.; OLIVEIRA, H. Controle sanitário na produção de perus. In: CONFERÊNCIA APINCO DE CIÊNCIA E TECNOLOGIA AVÍCOLAS, 2. 2006. Anais... Campinas: Facta, 2006, p.49-58.

BRASIL. Ministério da Agricultura e do Abastecimento. Secretaria de Defesa Agropecuária. Departamento de Inspeção de Produtos de Origem Animal. Regulamento da Inspeção Industrial e Sanitária de Produtos de Origem Animal (RIISPOA). Aprovado pelo Decreto n. 30.691, 29/03/52, alterado pelos Decretos $n^{\circ} 1255$ de 25/06/62, 1236 de 02/09/94, 1812 de 08/02/96 e 2244 de 04/06/97. Brasília, 2008.

BRASIL. Ministério da Agricultura, Pecuária e Abastecimento. Portaria $n^{\circ}$. 210 de 10/11/98. Regulamento técnico da inspeção tecnológica e higiênico-sanitária de carne de aves. Brasília, DF 1998. Publicado no Diário Oficial da União de 26/11/1998, Seção 1, p.226.

\section{Conclusões}

Conclui-se que a maioria das causas de condenação tanto total quanto parcial em perus abatidos na mesorregião do Triângulo Mineiro e Alto Paranaíba foi em função de causas infecciosas e não em função do manejo pré-abate incorreto (apanha transporte, pendura). Dessa forma, sugere-se uma melhoria do manejo sanitário ao longo da criação das aves, através do controle das enfermidades em nível de campo, a fim de reduzir o percentual destas condenações, sobretudo na primavera, estação do ano em que as condenações são mais frequentes.

CASTRO, A.G.M. Anamnese, diagnóstico clínico e anatomopatológico. In: BERCHIERI JÚNIOR, A.; MACARI, M. Doenças das aves. Campinas: Facta, 2000. Enfermidades do sistema respiratório. Cap. 2, p.71-74.

CEPEA, Centro de Estudos Avançados em Economia Aplicada, Escola Superior de Agricultura Luiz de Queiroz, Universidade de São Paulo. PIB do Agronegócio - BR, 2012. Disponível em: <http:// www.cepea.esalq.usp.br>. Acesso em 21, março, 2012.

DICKEL, E.L. Análise da inspeção ante-mortem e pós-mortem em abatedouro de aves. In: SIMPÓSIO BRASILEIRO DE SANIDADE AVÍCOLA DA UFSM, 5. 2006. Anais... Santa Maria, 2006, p.62-68.

FABRÍCIO, J.R. Influência do estresse calórico no rendimento da criação de frangos de corte. In: CONFERÊNCIA APINCO DE CIẾNCIA E TECNOLOGIA AVÍCOLAS, p.129-136, 1994, Campinas. Anais... Campinas, 1994.

FALLAVENA, L.C.B. Enfermidades da pele e das penas. In: BERCHIERI JUNIOR, A.; MACARI, M. Doenças das aves. Facta: Campinas, 2000, p.37-45. 
FERREIRA, A.J.P.; KNÖBL, T. Colibacilose. In: BERCHIERI JUNIOR, A.; MACARI, M. Doenças das aves. Facta:Campinas, 2000, p.197-203.

GIOTTO, D.B. Análise temporal e espacial de condenações de frangos de corte em matadouro-frigorífico. 2008. 115f. Dissertação (mestrado) - Universidade Federal de Santa Maria, Santa Maria, 2008.

HERENDA, D.C.; FRANCO, D. Poultry diseases and meat hygiene: a color atlas. lowa: lowa State University Press, 1996, 337p.

MACAHYBA, R.B.; MANO, S.B.; FREITAS, M.Q.; BAPTISTA, R.F. Condenações post-mortem em perus (Meleagris gallopavo) criados na Região Oeste Catarinense e abatidos sob Inspeção Federal. Revista Brasileira de Ciência Veterinária, v.12, n.1/3, p.53-57, 2005.

MCMULLIN, P.F.; BORIN, E.L.; AMARAL, N.K. Curso de patologia aviária. Campinas: Laboratório de diagnóstico Sousas, 1983, 95p.

MENDES, A.A. Jejum pré-abate em frangos de corte. Revista Brasileira de Ciência Avícola, v.3, n.3. Campinas, set/dez. 2001.

PULICI, R.; ALVES, F.R.; GAMEIRO, A.H. Aceitação e segmentação do mercado de produtos derivados de carne de peru. Sociedade brasileira de economia, administração e sociologia rural. Pirassununga, SP, 2008.
SCHLESTEIN, A. Avaliação das causas de condenações de perus (Meleagris gallopavo) em 2005 e 2006 no estado do Rio Grande Do Sul. 2007. 75f. Dissertação (Mestrado em medicina veterinária preventiva) - Faculdade de Medicina Veterinária - Universidade Federal de Santa Maria, Santa Maria, 2007.

TEIXEIRA, V.Q. Anatomopatologia e bacteriologia da pododermatite em frangos de corte sob Inspeção Sanitária. 2008, 51f. Dissertação (mestrado) - Faculdade de Medicina Veterinária) Universidade Federal Fluminense, Niterói, 2008. Disponível em: <http:www.uff.br/higiene_veterinaria/teses/vinicius_queiroz.pdf>. Acesso em 15 jul. 2011.

THORP, B. Fisiopatologia do aparelho locomotor: etiologias infecciosas. In: CONFERÊNCIA APINCO DE CIÊNCIA E TECNOLOGIA AVÍCOLAS, 1999. Anais... Campinas: Facta, 1999. p.1-6.

UBABEF - União Brasileira de Avicultura. 2011. Relatório Anual UBABEF 2010/2011. Disponível em: <http://www.abef.com.br/ubabef/ publicacoes_relatoriosanuais.php>. Acesso em 20 mar. 2012. 